\title{
Staub und Katzenhaare nur indirekt an Asthma-Entwicklung beteiligt
}

\begin{abstract}
Die Rolle der allergischen Sensibilisierung für die Entwicklung einer Asthmaerkrankung ist unbestritten. Fraglich ist dagegen, ob das

Auftreten des kindlichen Asthmas von der Konzentration von Innenraumallergenen in den ersten Lebensmonaten und Lebensjahren getriggert wird. Eine aktuelle Studie zeigt, dass beim kindlichen Asthma die Allergenkarenz möglicherweise nur in der Sekundärund Tertiär-, nicht jedoch in der Primärprävention Erfolg verspricht.
\end{abstract}

$\mathrm{D}$ ie prospektive Kohorten-Studie sollte zeigen, ob es tatsächlich einen Zusammenhang zwischen der steigenden Asthmaprävalenz bei Kindern und der Zunahme an Innenraumallergenen gibt. Seit 1990 wurden insgesamt 1.314 Neugeborene aus fünf deutschen Städten bis zu ihrem siebten Lebensjahr beobachtet. Bei 38\% der Kinder war das Asthmarisiko erhöht: Sie hatten wenigstens zwei Verwandte ersten Grades, die eine Atopie aufwiesen, oder erhöhte IgE-Werte im Nabelschnurblut $(>0,9 \mathrm{kU} / \mathrm{l})$.

Per Interview wurden kurz nach der Geburt familiäre Vorbelastungen, Risikofaktoren, sozialer Status und Anzahl der Geschwister abgefragt. Später machten die Eltern anhand eines strukturierten Fragebogens Angaben zu atopischen Symptomen und Erkrankungen des Kindes. Außerdem wurden jährlich Serum-IgE-Werte bestimmt. 6, 18 sowie 36 Monate nach der Geburt sammelten die Eltern nach einer definierten Methode Teppichstaubproben der Wohnräume. In einer Abschlussuntersuchung erfolgten Bestimmungen der Lungenfunktion und Provokationstests der Bronchien.

Es fand sich eine starke Assoziation zwischen dem Ausmaß der Allergenbelastung und der Sensibilisierung (erhöhte IgE-Werte). Außerdem wiesen Kinder mit Sensibilisierung gegenüber Milben- oder Katzenallergenen häufiger pfeifende Atemgeräusche und bronchiale Überempfindlichkeiten auf. Es ließ sich jedoch keine dosisabhängige Assoziation zwischen der Allergenbelastung in den ersten sechs Monate nach der Geburt und dem Auftreten pfeifender
Atemgeräusche bzw. der Asthma-Diagnose durch den Arzt nachweisen.

\section{Fazit}

Im Gegensatz zur Sensibilisierung scheinen bei der Entwicklung eines Asthmas nicht Innenraumallergene, sondern andere Faktoren die strukturellen Abnormalitäten in Atemwegen und Lungenparenchym auszulösen, die schließlich zur Erkrankung führen. Hat sich das Asthma n der Untersuchung von Pajno et al. bis 15 Jahren mit mildem bis moderatem Asthma und nachgewiesener Hausstaubmilben-Sensibilisierung nach einer einjährigen Beobachtungszeit für zwei Jahre randomisiert behandelt worden mit SLIT (Allergenlösung als Tropfen) oder Plazebo. Sowohl in der Beobachtungs-, als auch in der Behandlungszeit wurden Symptome und Medikation in Tagebüchern festgehalten sowie Milben-spezifischen IgE-, IgG- und IgG4-Antikörper gemessen. Nach den zwei Jahren waren asthmatische Symptome und Medikation in der SLIT-Gruppe signifikant geringer als in der Plazebo-Gruppe. Hinsichtlich der immunologischen Parameter

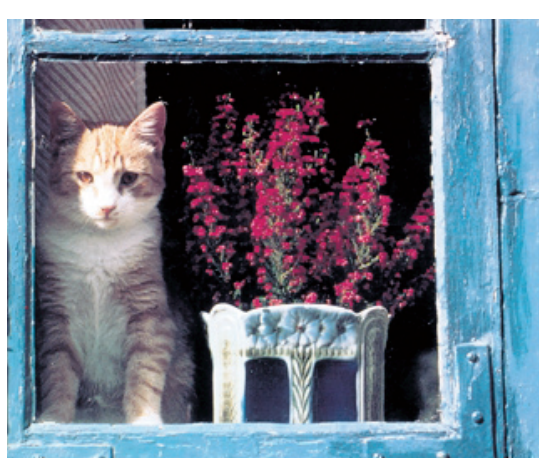

\section{Katzenhaltung ist nicht ursächlich für} Asthmaentwicklung verantwortlich.

jedoch entwickelt, steigt die Anfälligkeit, auf perenniale Allergene mit Sensibilisierung zu reagieren und diese Sensibilisierung wiederum ist klar assoziiert mit den Symptomen. Die Autoren werten ihre Ergebnisse als einen Paradigmenwechsel, der möglicherweise einen wichtigen Einfluss auf die Prävention haben könnte.

pe

\section{Lau $S$ et al.}

Early exposure to house-dust mite and cat allergens and development of childhood asthma: a cohort study. Lancet 2000; 356: 1392-7.

\section{Immuntherapie: Schlucken statt spritzen?}

\author{
Zwei doppelblinde, plazebokontrollierte Studien haben die \\ Effektivität der sublingualen Immuntherapie (SLIT) bei \\ Hausstauballergie überprüft. Zu einem eindeutigen Ergebnis kom- \\ men sie allerdings nicht.
}

ergaben sich allerdings keine Unterschiede.

Guez et al. behandelten 75 Patienten im Alter von sechs bis 51 Jahren mit perennialer Rhinitis (mit/ohne Asthma), bei denen die Hausstaubmilbe das Hauptallergen war, für zwei Jahre randomisiert mit Plazebo oder SLIT. Das Verum bestand aus einer 50:50-Präparation, die Dermatophagoides pteronyssinus und $\mathrm{D}$. farinae enthielt. Jeder Patient bekam im Durchschnitt eine kumulative Dosis von 90.000 IR. Wieder wurden Symptome und Medikation in einem Tagebuch festgehalten und spezifische IgEsowie IgG4-Werte sowohl vor, als auch 12 und 24 Monate nach Therapiebeginn bestimmt. 